A N A K R E O N S

\title{
AUSERLESENE ODEN,
}

V N D

DIE ZWEY NOCH ÜBRIGEN ODEN

DER

S A P P H O.

MIT ANMERKUNGEN

vor

KARL WILHELM RAMLEF.

Für diesen Titel wird der in Kupfer gestochne, und für das letzte Blatt das einzeln beigelegte mit einer Vignette, eingeklebt.

Preis: $16 \mathrm{Gr}$. Preufsisch.

- auf Velinpapier I Thlr.

B E R I I N,

BEY JOH. DAN. SANDER.

1801 . 
